\title{
A Reforma do Estado e a política de descentralização da educação no contexto na década de 1990
}

\author{
State Reform and the policy of decentralization \\ of education in the context in the 1990s
}

Inalda Maria dos Santos

Doutora em Educação pela Universidade Federal de Pernambuco Docente do Programa de Pós-Graduação em Educação da Universidade Federal de Alagoas. Maceió - AL - Brasil inaldasantos@uol.com.br

Resumo: O presente artigo visa problematizar a política de descentralização da educação no contexto da Reforma do Estado, empreendida na década de 1990, tendo como expressão o Programa Dinheiro Direto na Escola. Como metodologia de pesquisa, adotamos uma abordagem qualitativa e bibliográfica acerca do objeto analisado a partir de teóricos como Rosanvallon (1997), Nogueira (1998), Casassus (1995), Melo (1997), Andrade (1998), Arretche (1997), dentre outros. Considerando a relevância e atualidade da temática, ressaltamos a importância da problematização das questões abordadas e da necessidade do amplo debate acerca das repercussões do ajuste fiscal e todas as estratégias delineadas no projeto da Reforma do Estado, uma vez que essas questões conseguem clarificar o contexto atual da política e do Estado brasileiro.

Palavras-chave: Reforma do Estado. Política de Descentralização. Educação.

\begin{abstract}
This article aims to problematize the policy of decentralization of education in the context of State Reform undertaken in the 1990s, using the Direct Money in School Program as an expression. As a research methodology, we adopted a qualitative and bibliographical approach about the object analyzed from the theorists such as Rosanvallon (1997), Nogueira (1998), Casassus (1995), Melo (1997), Andrade (1998), Arretche (1997) among others. Considering the relevance and timeliness of the theme, we emphasize the importance of the problematization of the issues addressed and the need for a broad debate about the repercussions of the fiscal adjustment and all the strategies outlined in the State reform project, since these issues can clarify the current context politics and the Brazilian State.
\end{abstract}

Keywords: State Reform. Decentralization Policy. Education. 


\section{Introdução}

Na discussão sobre a Reforma do Estado, o tema da descentralização vem sendo proclamado como um avanço democrático e, nessa perspectiva, toma-se o ideal da participação direta como uma expressão da democracia. Entretanto, como adverte Lander (1999), a descentralização tem "origens teóricas $e$ políticas diversas, e suas consequências para a democracia não são de maneira alguma unívoca" (p. 467, grifo do autor). O que significa dizer que a compreensão do que seja uma política de caráter descentralizador poderá estar assumindo a conotação de uma desconcentração, uma vez que são conceitos que se confundem na prática.

Partindo desse pressuposto, inscreve-se o presente artigo, que visa problematizar a política de descentralização da educação no contexto da Reforma do Estado brasileiro a partir da década de 1990. Para tanto, como metodologia de pesquisa, adotamos uma abordagem qualitativa e bibliográfica acerca do objeto analisado, a partir de teóricos como Rosanvallon (1997), Nogueira (1998), Casassus (1995), Melo (1997), Andrade (1998), Arretche (1997) dentre outros, por entender que esses autores tiveram uma produção teórica relevante para a compreensão do contexto político e econômico que forjaram a implementação da Reforma do Estado nos anos 1990.

\section{Contexto da Reforma do Estado Brasileiro na década de 1990}

Como mostra a literatura que tem estudado o tema da Reforma do Estado, a partir do final dos anos 1970 tiveram início, no plano mundial, as mudanças no padrão de intervenção estatal, quando os novos rumos imprimidos às economias capitalistas colocaram em xeque o modelo keynesiano de regulação, que se pautava, por um lado, na consolidação de um Estado protetor e, por outro, na constante negociação das relações capital x trabalho (ROSANVALLON, 1997; HARVEY, 1988; IANNI, 1997).

Essas mudanças, por sua vez, passaram a ocorrer como uma maneira de buscar superar a crise, que, a partir dos anos 1970, passou a afetar o mundo capitalista e, por consequência, atingiu o Estado providência que se afirmara nos países 
centrais, ou de capitalismo avançado, conduzindo a uma redefinição da relação entre Estado e Sociedade. Nesse sentido, Rosanvallon (1997) afirma que, com a crise do Estado providência, há uma substituição da lógica da estatização por uma lógica particularizada à socialização, à descentralização e à autonomização daquelas relações e, portanto, do modo de atuação do Estado na implementação das políticas públicas.

Embora no Brasil, e nos demais países de capitalismo periférico, o Estado providência não tenha se afirmado, a intervenção estatal na economia e na regulação das relações capital e trabalho tinham levado a um tipo, mesmo restrito, de proteção social com políticas públicas correspondentes (AZEVEDO, 1997). No entanto, devido à nossa participação no espaço capitalista mundial, como país subordinado, fomos também afetados pela crise e pelas soluções implantadas na busca da sua superação. Foi nesse contexto onde a Reforma do Estado brasileiro passou a ganhar centralidade, a partir do final da década de 1980.

A partir da década de 1980, fatores como o desequilíbrio fiscal, desordem das contas públicas, instabilidade monetária foram identificados como geradores da crise, levando a tentativa de ajuste estrutural que foi introduzido na agenda pública nos últimos dez anos do final do século XX.

Nesse contexto, o rebatimento, no campo educacional, dos efeitos da Reforma do Estado ${ }^{1}$ tem tido por pressuposto a necessidade de se consolidar um modelo de desenvolvimento que se paute, por um lado, numa sociedade educada e, por outro, numa economia altamente competitiva, de forma que o progresso signifique o modo mais avançado de uma nação produzir. É nesse sentido que o "Plano Diretor da Reforma do Aparelho do Estado" registrou a necessidade de "modificar a ação do Estado, de tal modo que sua intervenção reguladora, em cada setor específico, se tornasse eficaz. A intenção central era reconstruir a própria administração pública em novas bases modernas e racionais" (FREITAS, 2000, p. 89). Isso de acordo com o entendimento que a "modernidade" e a "racionalidade" passam a ter no projeto de sociedade do grupo no poder.

É oportuno, nesse ponto, uma referência sobre a distinção que é feita entre a Reforma do Estado e a reforma do aparelho do Estado, essa última também chamada reforma administrativa do Estado. A Reforma do Estado é entendida "dentro do contexto da redefinição do papel do Estado, que deixa de ser o responsável direto pelo desenvolvimento econômico e social pela via da produção 
de bens e serviços, para fortalecer-se na função de promotor e regulador desse desenvolvimento" (BRASIL, 1995, p. 17).

Enquanto que a reforma do aparelho do Estado ${ }^{2}$, refere-se a uma orientação do governo para tornar a administração pública mais eficiente e voltada para a cidadania, que é entendida, nesse contexto, como o atendimento ao cidadãocliente, ou seja, o cidadão sendo aquele que contribui com os impostos e, ao mesmo tempo, como cliente dos serviços estatais.

Neste cenário, os princípios que orientaram a Reforma do Estado na década de 1990 foram: desburocratização, descentralização, transparência, accountability, profissionalismo, ética, competitividade e a ênfase no cidadão-cliente. Além disso, foi eleito o modelo gerencial de gestão, tido como meio de profissionalizar e otimizar os serviços públicos, entre os quais, os serviços de educação.

Em síntese, o discurso do governo apoiou-se na ideia de que o Estado funcionava mal, perdendo sua capacidade de coordenação e que, portanto, precisava, urgentemente, reformar suas bases, sua cultura organizacional e seus procedimentos. Assim, o projeto da Reforma do Estado revelou a necessidade de uma reforma política, trazendo consigo uma nova relação do Estado com a Sociedade. Nesse sentido, segundo Nogueira (1998), a reforma foi identificada como uma forma de "desprivatizar o Estado, de modo a colocá-lo a serviço dos interesses da sociedade, democratizar seu controle e responsabilizá-lo" pelas ações públicas (FREITAS, 2000, p.156).

Entretanto, como nos adverte Nogueira (1998, p. 156), essa é uma visão superficial e redutora da complexidade que envolve o processo de implementação da reforma, pois:

Embora fosse efetivamente uma meta fundamental e inadiável, a reforma da administração só poderia ser efetivada como parte de um projeto mais amplo que, no essencial, trouxesse em si um novo desenho de Estado, um novo método de gestão das atividades públicas, uma nova institucionalidade política, um novo padrão de relacionamento Estado/Sociedade, em suma, a recuperação da esfera pública enquanto tal.

Concordamos com as análises de Nogueira (1998), quando ele ressalta que a orientação mais geral do projeto da Reforma do Estado, implementado 
no primeiro governo de Fernando Henrique Cardoso, em 1995, contém traços do neoliberalismo, por defender a descentralização da gestão como uma desresponsabilização, a transferência de atribuições públicas para os setores privados, e outras medidas que beneficiaram o capital e o mercado, aumentando os níveis de exploração e exclusão.

Nessa mesma direção, Silva Júnior (1996), no artigo intitulado "A ideologia da incompetência de outras ideologias de conveniência na relação neoliberalismo e educação", argumenta que tal como as ideologias de conveniência, a ideologia da incompetência cumpre a função de 'despublicizar' o interesse público, de 'deslegitimar' o Estado como provedor desse interesse, de 'desregulamentar' os organismos do Estado a fim de facilitar a 'reengenharia' de seus mecanismos e de seus procedimentos". Nesse sentido, a ideologia da incompetência diz respeito ao que se convencionou chamar de "neoliberalismo", e essa por sua vez, refere-se à ideologia da flexibilização que, por seu turno:

Cumpre a função primordial de preparar o terreno para a supressão de garantias institucionais e constitucionais destinadas ao exercício de direitos consagrados pelas lutas históricas dos trabalhadores e de toda a humanidade. Em nome da 'globalização' - outra ideologia - e da 'nova qualificação para o trabalho' - ainda outra ideologia - flexibilizar significa desempregar e administrar significa desestabilizar. Produzir pode significar simplesmente 'terceirizar' (SILVA JÚNIOR, 1996, p. 75-76).

Em suma, vale a pena ressaltar que, a rigor, pensar numa Reforma do Estado que possa compreender a complexidade da administração pública consiste em não a pensar como algo que dependeria de uma só vontade política ou que a sua realização aconteceria numa única gestão governamental. Isso porque não se deve reduzir a ideia de Reforma do Estado à ideia de uma reforma da administração, pois, a solução para os problemas passa pela "construção de consensos, pactos políticos e projetos e requer o alcance de um equilíbrio dinâmico entre vontade política e razão crítica" (NOGUEIRA, 1998, p.179).

Entretanto, é nesse contexto que têm se inserido as mudanças na gestão das políticas de educação, as quais, por sua vez, se articulam às mudanças nos padrões da regulação estatal e, portanto, das políticas públicas no seu conjunto. 
No que se refere à gestão da educação, um dos aspectos que vêm tendo destaque é a ênfase no princípio da descentralização, que se vincula diretamente aos conceitos de democratização, participação e autonomia escolar.

\section{Controvérsias acerca do conceito de descentralização: uma introdução}

Analisando a temática da descentralização, Abranches apud Sato (1993) afirma que a descentralização política requer a democratização do processo decisório, o que prescinde de uma participação e criação de instrumentos de representação da população junto ao governo.

Por outro lado, Tobar apud Sato (1993) adverte que a mera transferência de poder, entre as esferas federal, estadual e municipal, não caracteriza um processo de descentralização, pois a "efetivação do repasse de recursos financeiros, mantendo a centralização do conhecimento técnico-científico, só beneficia as unidades locais que tenham um aparelho técnico-científico desenvolvido e, além disso, corre-se o risco de estar favorecendo sistemas clientelistas e personalistas locais". Em suma, para ele a descentralização é capaz de promover resultados tanto positivos como negativos.

Casassus (1995, p. 84), por sua vez, compreende a "desconcentração" e a "descentralização" como processos distintos, que se relacionam com o modo de exercício do poder nas distintas esferas administrativas:

[...] a desconcentração, reflete processos cujo objetivo é assegurar a eficácia do poder central, ao mesmo tempo que o outro, a descentralização, é um processo que tende a assegurar a eficácia do poder local. Desta maneira, a desconcentração reflete um movimento cujo sentido é 'de cima para baixo', ao tempo que a descentralização refletiria o movimento contrário, 'de baixo para cima'.

Neste sentido, o autor, ao considerar o movimento da descentralização, adverte sobre a necessidade de se ter como referência o processo de centralização, pois ambos tratam da questão do poder e da forma como a sociedade se organiza: 
[...] são processos de distribuição, redistribuição ou reordenamento do poder na sociedade, nos quais há acrescentamento de poder para uns ou decréscimo para outros, onde se incluem ou se reconhecem novos atores e onde surgem outros, ou onde se definem novas formas e áreas de poder na sociedade (CASASSUS, 1995, p. 96).

Portanto, para se entender a descentralização como tema de poder, faz-se necessário perceber o tipo de diálogo social que prevalece numa sociedade. Assim, quando não se reconhece a dimensão do poder nesses processos (centralização/ descentralização), passa a se desconhecer também a necessidade de negociação e de mobilização do conjunto das forças ativas na sociedade, bem como o fato de que há uma luta entre estes para conseguir adesão, para que, assim, um dos processos possa vir a se concretizar.

Entendermos, pois, o processo descentralização como um tema complexo implica em compreendê-lo, tanto a partir da delegação de competências e responsabilidades, quanto no que se refere à tomada de decisão na implementação de uma política de Estado e em atentar para a finalidade a que essa se propõe. Nesses termos, na visão de Casassus (1995), o problema, quando se toma a decisão de descentralizar, é que sua dinâmica de execução tende, na maioria das vezes, a fazer dela um fim. Nisso consiste o seu caráter instrumental, ligado a uma ideia de poder, que traz repercussões na gestão da política.

Numa outra forma de abordar a questão da descentralização situa-se a posição de Andrade (1998, p.120), ao afirmar que a Constituição de 1988 consolida a tendência descentralizadora, vigente na pauta de reivindicações apresentada à Assembleia Constituinte. Na nova Carta, chamada de Constituição Cidadã, foi definido o "novo arranjo federativo para o país, com significativa transferência de funções, poder decisório e recursos, do plano federal para estados e municípios".

Para Andrade (1998), a descentralização deve promover as condições da capacidade de gestão do poder local e ampliar o sistema de tomada de decisões, de modo a aproximar a função pública do cidadão. Entretanto, na prática, os processos de descentralização têm sentidos diferentes. Ora como desconcentração, entendida como municipalização de algumas políticas, ora como descentralização propriamente dita, ou seja, aquela que supõe a democratização da tomada 
de decisões em relação a algumas áreas de política social: educação, saúde, assistência social, entre outras.

De uma perspectiva mais ampla, Melchior (1997), com base em estudos sobre o financiamento da educação, ressalta que as experiências vivenciadas nas unidades escolares brasileiras, caracterizam-se muito mais como desconcentração de poder do que descentralização, como proclamado pela política educacional.

Em suas palavras:

As experiências vividas atualmente, que visam a uma maior autonomia da unidade escolar, não podem ser confundidas com o processo de descentralização. Descentralização, no âmbito das esferas públicas, é uma repartição ou delegação de poder que vai das esferas maiores para as menores. Assim, a União descentraliza para os Estados e Municípios e os Estados para seus Municípios. As experiências vividas de autonomia da unidade escolar são experiências de desconcentração de poderes dos órgãos centrais para a periferia, de órgãos da Secretaria da Educação para as unidades escolares. São ainda experiências limitadas pela legislação centralizadora que ainda vigora no país (MELCHIOR, 1997, p. 32).

Nesse sentido, encontramos divergências entre o conceito de descentralização, tal como até aqui problematizado, e o modo como o mesmo está sendo utilizado pelo discurso governamental, e operacionalizado nas medidas de política educacional, concernentes. Essas diferenças podem ser mais bem apreendidas quando articuladas ao contexto mais amplo em que vêm se inserindo as reformas educacionais brasileiras.

\subsection{A política de descentralização da educação}

O tema da descentralização tem se tornado, de forma notável, pauta de discussão das políticas públicas, e constitui-se um dos aspectos centrais da agenda governamental, ao mesmo tempo em que é uma questão que vem sendo problematizada pelos estudiosos das políticas públicas, e surge no cenário nacional com maior força na década de 1980, dentro do jogo político da democracia em que ele se insere. 
É no contexto de redemocratização do país, tendo como pano de fundo a Constituição de 1988, que se estabelece o princípio da descentralização administrativa, passando o município a integrar a Federação, o que leva a associar a descentralização à municipalização (Art. 18).

Durante o governo Sarney, a questão da descentralização ressurge articulada ao debate sobre as reformas setoriais e se baseava em propostas voltadas para a construção de uma democracia social no país, contrapondo-se ao extremo centralismo que caracterizou a ação do Estado durante a ditadura militar. Segundo Arretche (1997, p. 142), nesse período se propunha:

A descentralização e regionalização dos programas nacionais de saneamento e habitação; a descentralização, universalização e democratização dos programas de educação básica; o abandono das práticas clientelistas e a municipalização da assistência social como forma de que a prestação de serviços assistenciais equivalesse a um direito de cidadania; a unificação e descentralização de um sistema nacional de saúde capaz de universalizar o atendimento à população.

Naquele momento, entretanto, a descentralização não foi um princípio apenas defendido pelas chamadas forças progressistas. Como enfatiza Melo (1998), os defensores da redução do papel do Estado, os neoliberais, em consonância com as agências internacionais de desenvolvimento, passaram também a defender o princípio da descentralização como um meio de diminuir a ação estatal na prestação dos serviços públicos.

Esse debate influenciou as decisões registradas na Constituição de 1988, bem como as prescrições contidas na Lei de Diretrizes e Bases da Educação promulgada em 1996, que forneceram as bases legais para que o governo empreendesse a descentralização.

No âmbito da política educacional brasileira, a partir da década de 1990, destaca-se a elaboração do documento Planejamento Político Estratégico, do MEC (1995-1998), que faz referência ao papel da municipalização desconcentradora e o seu papel político na reorganização da sociedade civil.

É neste contexto em que vai se inserir o governo de Fernando Henrique Cardoso. Com efeito, foi com o lançamento do projeto "Acorda Brasil, Está na 
Hora da Escola"3, em março de 1995, que esse governo iniciou as medidas proclamadas como um meio de "descentralizar" a gestão educacional. O tema da descentralização, nesse contexto, encontrava-se ligado às novas formas de articulação entre o Estado e a Sociedade, em que se salienta a necessidade da Reforma do Estado, que significava aprofundar a democratização, acelerar o processo de descentralização e desconcentração e, sobretudo, ampliar e modificar suas formas de relacionamento com a sociedade, definindo novos canais de participação.

De acordo com Silva Júnior (2004), há um discurso em defesa da transferência de deveres do Estado e dos direitos sociais e subjetivos do cidadão para a sociedade civil, particularmente naquelas tarefas do âmbito da União. Ou seja, há nesse movimento uma ressignificação da cidadania, que passa de um espaço de usuário do Estado, como no fordismo, para de clientes da instituição que produz a política e a fundação de um novo pacto social baseado nos novos paradigmas econômicos.

Nessa perspectiva, o debate em torno dos fundamentos das políticas descentralizadas constitui, a partir da década de 1990, questão recorrente entre estudiosos da política educacional brasileira. Assim, tentar compreender a complexidade que envolve o processo de centralização e descentralização implica em perceber que existem controvérsias acerca da compreensão desses processos.

No que diz respeito à descentralização da educação, sua manifestação mais expressiva é a Emenda Constitucional no 14 (EC 14/1996), que estabeleceu o Fundo de Manutenção e Desenvolvimento do Ensino Fundamental e de Valorização do Magistério (FUNDEF), regulamentado pela Lei 9.424/96.

Neste contexto, no campo educacional foram implantadas medidas de políticas de descentralização da educação, justificadas como meio de possibilitar mais autonomia para a escola e promover melhorias na qualidade do ensino público. Dentre as mudanças implantadas pelo Ministério da Educação (MEC) desde o primeiro governo de Fernando Henrique Cardoso, no ano de 1995, destacamos o Programa Dinheiro Direto na Escola ${ }^{4}$ como política de descentralização, que trata da transferência de recursos federais às escolas públicas da rede municipal, estadual e do Distrito Federal do ensino fundamental, como também às organizações não-governamentais, sem fins lucrativos, voltadas à educação especial. A regulamentação do Programa Dinheiro Direto na escola, ocorreu no período da sua criação, através da Resolução $n^{\circ}$ 03, de 04 de março 
de 1997, que, dentre outras coisas, determinou a constituição de "Unidades Executoras".

A Unidade Executora a quem cabe receber e gerir os recursos, consiste numa entidade de direito privado, sem fins lucrativos, representativa da comunidade escolar e pode ser criada a partir de uma Associação de Pais e Mestres, de uma Caixa ou de um Conselho Escolar.

Essas e outras medidas se inserem no movimento da descentralização, cujo significado se relaciona com as relações de poder que predominam num determinado contexto social.

Diante desse cenário, trabalhos teóricos (MELO, 1997; ANDRADE, 1998; ARRETCHE, 1999; CASASSUS, 1995), vêm apontando que as experiências de descentralização consistem muito mais em medidas de desconcentração, tendo em vista que a formulação e o controle das políticas públicas ainda continuam centralizadas no poder do governo central, sendo descentralizadas a operacionalização e prestação de contas dos recursos públicos.

\section{Considerações finais}

Diante do exposto, procuramos demonstrar que os conceitos de descentralização não possuem apenas um significado, e que a nossa compreensão sobre este tinha por suposto a democratização substantiva das relações entre o Estado e a Sociedade. Essa compreensão, por sua vez, implica no rompimento dos padrões tradicionais da gestão pública, o que envolve não apenas mudanças nas relações de poder entre as instâncias administrativas Federal, Estadual e Municipal, como também entre os atores locais, que devem contar com canais onde possam participar das decisões, num processo de cogestão propiciado pelo alargamento do espaço público (SILVA, 1996; FISCHER, 1993; GENRO, 1996).

Neste contexto, salientamos que a política de descentralização empreendida na educação brasileira, desde a década de 1990, apresenta limites e perspectivas. O Programa Dinheiro Direto na Escola, que vem sendo reformulado desde a sua criação, apesar das críticas que recebe (FRANÇA, 2005; ADRIÃO; PERONI, 2007; SILVA, 2015), é uma política que tem forte presença nas escolas públicas de todo o país e, mesmo com limites financeiros, atende as demandas e necessidades da escola pública. 


\section{Notas}

1 Luiz Carlos Bresser Pereira, Ministro da Administração Federal e Reforma do Estado, no ano de 1995, anuncia as diretrizes e linhas de atuação da Reforma do Estado brasileiro.

2 O "aparelho do Estado" é composto pela estrutura organizacional do Estado, ou seja, os três Poderes (Executivo, Legislativo e Judiciário) e os três níveis (União, Estados e Municípios), por um corpo de funcionários e pela força militar. Num sentido amplo, o "aparelho do Estado" é a Administração Pública.

3 Articulado a esse projeto, o governo federal lança a nível nacional o Programa "Dinheiro na Escola", na época vinculado ao PMDE (Programa de Manutenção e Desenvolvimento do Ensino Fundamental). O FNDE (Fundo Nacional de Desenvolvimento da Educação) é o órgão responsável pela transferência dos recursos financeiros da União para todas as escolas públicas do país. O Programa justifica-se como um meio de construção da gestão democrática, dentro do princípio de estabelecer a autonomia financeira, administrativa e pedagógica das unidades escolares.

4 O Programa Dinheiro Direto na Escola (PDDE) já sofreu várias alterações desde a sua criação, como, por exemplo, o repasse de recursos para as escolas privadas de educação especial sem fins lucrativos e a ampliação para toda a educação básica pública.

\section{Referências}

ANDRADE, Ilza Araújo Leão de. Descentralização e poder municipal no Nordeste: os dois lados da nova moeda. In: SOARES, José Arlindo (Org.). O orçamento dos municípios no nordeste brasileiro. Paralelo 15, 1998.

ADRIÃO, Theresa; PERONI, Vera. Implicações do Programa Dinheiro Direto na Escola para a gestão da escola pública. Revista Educação e Sociedade. Campinas, v. 28, n. 98, p. 253-267, jan./abr. 2007. Disponível em: < http://www.scielo.br/pdf/es/v28n98/a13v2898.pdf>. Acesso em: 24 set. 2014.

ARRETCHE, Marta. O mito da descentralização como indutor de maior democratização e eficiência das políticas públicas. In: GERSCHMAN, Silvia; VIANNA, Maria Lucia Werneck. A miragem da pós-modernidade: democracia e políticas sociais no contexto da globalização. Rio de Janeiro: FIOCRUZ, 1997.

ARRETCHE, Marta. Políticas sociais no Brasil: descentralização em um Estado federativo. Revista Brasileira de Ciências Sociais. v. 14, n. 40. São Paulo: ANPOCS, 1999.

AZEVEDO, Janete Maria Lins de. A educação como política pública. Campinas: São Paulo, 1997.

BRASIL. Constituição da República Federativa do Brasil - 1988. Centro Gráfico do Senado Federal. Brasília, 1988.

BRASIL. Plano Diretor da reforma do aparelho do Estado. Brasília: Presidência da 
República, Câmara da Reforma do Estado, Ministério da Administração Federal e Reforma do Estado, 1995.

CASASSUS, J. Tarefas da educação. Campinas: Autores Associados, 1995.

FISCHER, Tânia (Org.) Poder local: governo e cidadania. Rio de Janeiro: Fundação Getúlio Vargas, 1993.

FRANÇA, Magna. Gestão e financiamento da educação: o que mudou na escola? Programa Dinheiro Direto na Escola - FUNDEF. Natal: EDUFRN, 2005. 243 p.

FREITAS, Alexandre Simão de. A crise do imaginário moderno e as novas tecnologias de regulação do trabalho docente: discurso, conhecimento e poder o Programa Pró-Ciências Pernambuco. Recife: UFPE, Mestrado em Educação, 2000 (Dissertação de Mestrado).

GENRO, Tarso. O novo espaço público. 21 teses para a criação de uma política democrática e socialista. Folha de São Paulo, 09/06/96, Caderno Mais.

HARVEY, D. Condição pós-moderna. São Paulo: Loyola, 1988.

IANNI, O. A era do globalismo. Rio de Janeiro: Civilização Brasileira, 1997.

LANDER, Edgardo. Limites atuais do potencial democratizador da esfera pública não-estatal. In: BRESSER PEREIRA, L. C.; GRAU, Nuria C. O público não-estatal na reforma do Estado. Rio de Janeiro: Fundação Getúlio Vargas, 1999.

MELCHIOR, José Carlos de Araújo. Mudanças no financiamento da educação no Brasil. Campinas: Autores Associados, 1997.

MELO, Marcus André B. C. Crise Federativa, Guerra Fiscal Hobbesianismo Municipal: efeitos perversos da descentralização?. In: OLIVEIRA, Marcos Aurélio Guedes de (Org.). Política e Contemporaneidade no Brasil. Recife: Bagaço, 1997.

MELO, Marcus André B. C. Estado, governo e políticas públicas. In: MICELI, Sergio (Org.). O que ler na ciência social brasileira (1970-1995). São Paulo: Sumaré/ANPOCS: Brasília, DF: CAPES, 1998.

NOGUEIRA, Marco Aurélio. As possibilidades da política: ideias para a reforma democrática do Estado. São Paulo: Paz e Terra, 1998.

SATO, Ademar K. Descentralização: um tema complexo. Texto para Discussão, no 314, out. 1993. Brasília: IPEA, 1993.

SILVA, Givanildo da. O Programa Dinheiro Direto na Escola (PDDE) como mecanismo da descentralização financeira, participação e autonomia na Gestão Escolar. 2015. 134 f. Dissertação (Mestrado em Educação) - Universidade Federal de Alagoas. Centro de Educação. Programa de Pós-Graduação em Educação. Maceió, 2015.

SILVA, Leonides Alves da. Para que participação popular nos governos locais? São Paulo: Instituto Pólis/Instituto Cajamar/IBASE/FASE, fev, 1996. (Apresentação).

SILVA JÚNIOR, Celestino Alves da. A ideologia da incompetência do outro e outras ideologias de conveniência na relação neoliberalismo e educação. In: GHIRALDELLI JUNIOR, Paulo (Org.). Infância, educação e neoliberalismo. São Paulo: Cortez, 1996. (Coleção questões da nossa época, v. 61). 
SILVA JÚNIOR, João dos Reis. O papel político da municipalização educacional na construção dos novos traços da sociedade civil na década de 1990. In: MARTINS, Ângela; OLIVEIRA, Cleiton de \& BUENO, Maria Sylvia Simões. Descentralização do Estado e Municipalização do Ensino: problemas e perspectivas. Editora DP\&A, 2004.

ROSANVALLON, Pierre. A crise do estado-providência. Brasília: UnB, 1997.

recebido em 14 mai. 2017 / aprovado em 31 jan. 2018

Para referenciar este texto:

SANTOS, I. M. A Reforma do Estado e a política de descentralização da educação no contexto na década de 1990. Dialogia, São Paulo, n. 29, p. 125-138, mai./ago. 2018. Disponível em: <https://doi.org/10.5585/Dialogia.n29.7409>. 